John Carroll University

Carroll Collected

Sociology

2011

\title{
The Journal's 10 year anniversary - looking back and moving forward
}

Phyllis Braudy Harris

John Carroll University, pharris@jcu.edu

John Keady

Follow this and additional works at: http://collected.jcu.edu/soc-facpub

Part of the Family, Life Course, and Society Commons, and the Medicine and Health Commons

\section{Recommended Citation}

Harris, Phyllis Braudy and Keady, John, "The Journal's 10 year anniversary - looking back and moving forward" (2011). Sociology. 7. http:// collected.jcu.edu/soc-facpub/7

This Editorial is brought to you for free and open access by Carroll Collected. It has been accepted for inclusion in Sociology by an authorized administrator of Carroll Collected. For more information, please contact connell@jcu.edu. 
The Journal's 10 year Anniversary - Looking back and moving forward
Dementia

I0(I) 3-6

(C) The Author(s) 2011

Reprints and permissions: sagepub.co.uk/journalsPermissions.nav DOI: 10.1।77/147130121|401685 dem.sagepub.com

(SAGE

\section{Phyllis “Penny" Braudy Harris and John Keady}

This issue marks the 10th year of the Journal, whose guiding mission has been, "To provide a major international forum for social-behavioral research and practice that has direct relevance on improving the quality of life (QOL) and quality of care for people with dementia and their families" (Keady \& Harris, 2002). For where the main focus of biomedical research has been on the cause of dementia, the focus of social-behavioral research is on the consequences of living with dementia. On a daily basis, persons with dementia and their family members must face alone and together this "lived experience," with its ever constant changes, surprises, challenges, disappointments, and sometimes rewards; and most of all they must learn to cope. Social-behavioral research can help.

Pearlin et al. (2001) identified five research domains essential for future social research on the consequences of dementia: 1) the person with dementia, 2) the family and household, 3) the physical and social environment, 4) effective services and interventions, and 5) directions for health policy. This schematic was presented as a heuristic device to stimulate thinking about future research. Over the years, this Journal has played an important role in publishing articles that further deepened our understanding in all five recommended research areas. Reviewing the Journal's last 10 years of publications, below are just a few examples of articles that reflect research in each of the domains.

Articles in the Journal have increased our understanding of the "inner worlds" of both the person with dementia and their care partner. Articles that explored "the inner world" of people with dementia were ones such as: 1) the very first paper published by the Journal, Sterin's (2002) eloquent personal essay on how being diagnosed with dementia and the stigma that entailed, forever changed one's social interactions and self-concept; Krause's and Moyer's (2006) discussion on how her diagnosis spurred them into becoming advocates for people with AD, and the meaning such work has brought to their lives; and Fazio's and Mitchell's study (2009), which demonstrated through evidence from remaining language and visual recognition that the self of the person with Alzheimer's disease persists along the journey, expanding the work of Steven Sabat (2001). Each article and many others deepened our understanding of the lived experience.

A few notable articles about the "inner world" of carer experience were: 1) Weyl's (2009) description of her journey with her husband Peter diagnosed with AD, as she loves and cares for him, and copes, recorded in a memoir, entitled, "Love song at the end of the day"; 2) Aubeeluck's and Buchanan's (2006) article that captured the Huntington's disease spousal carer experience, a group that is often forgotten, using the methodology of photovoice. This study visually presented the carers' quality of life, encompassing loss, loneliness, neglected needs and desire for escape; and 3) one of the most unique articles published over the years, 
an article (and accompanying Editorial) by Parker, Young and Rogers (2010) in which a Deaf daughter described her Deaf mother's experiences with dementia, focusing on the problematic nature of recognizing dementia amongst Deaf people and the lack of appropriate diagnostic, care and support services. For Jacqueline Parker's mother to die in an environment where she was not understood and where no specialist services existed to interpret her communication and language is a reality which should stop us all in our tracks and ask the most searching of questions. These articles plus so many of other published in the Journal expanded our understanding of the care partner's perspective and their varied service needs.

In the realm of physical and social environmental effects on people with dementia, there were published studies such as: 1) the research by Cloffi, Fleming, Wilkes, Sinfield, and Le Mlere (2007) where through conducting focus groups with families and staff, researchers were able to document positive changes in behavior and functioning of residents in a special care unit when smaller more home-like units were initiated; 2) Van Hoof's and Kort's (2009) concept paper on designing a dementia friendly home in terms of architectural features, interior design, the indoor environment, and technological assistive devices all to facilitate people with dementia to remain independent and in their own homes as long as possible; and 3) Davis, Byers, Nay, and Koch (2009), who in their article argued that it is the lived experience of people with dementia that should guide the building of residential facilities suggesting seven living experiences to be considered in architectural design: eating, bedroom, family and community connections, personal enjoyment, staff, and end-of -life experiences.

As relates to service and intervention studies to improve quality of life and quality of care, the Journal published research such as:1) Tremont's, Davis', Bishop's, and Fortinsky's (2008) randomized control pilot study on a new accessible and low cost telephone psychosocial intervention to reduce caregiver burden, which showed much promise; 2) Hicks-Moore's and Robinson's (2008) randomized control study on the use of hand message and music to lessen agitation in nursing home residents, where the data demonstrated some significant results; and 3) Malone's and Camp's (2007) work on Montessori-based dementia programming with residents in various institutional settings that used individually designed every day type activities, based on a person's past interests, which positively reinforced remaining skills.

In the domain of health policy, articles such as: 1) Wilkinson's and Weaks' (2008) editorial on the collaboration between Scottish policy makers, researchers, practitioners, people with dementia, and their families demonstrated how meaningful policy that impacts quality of life can be co-created; 2) Iliffe's and Manthorpe's (2007) discussion of England's National Institute of Health and Clinical Excellence and the Social Care Institute for Excellence guidelines on providing quality dementia care provided a insightful review and critique of a national policy, one of the few national policies on dementia care; and 3) Cayton's (2004) use of narratives as a way to inform and question the choices and challenges societies must make as they struggle to care for and develop policy to protect the rights and dignity of people with dementia.

So, yes, over the last 10 years the Journal has published articles in the five major domains of social-behavioral research and pushed the knowledge base further, and yet the Journal has done more than that. The Journal has also focused on the needs of special groups within the dementia population, who get little attention. The Journal published special issues devoted to people with intellectual difficulties affected by dementia, issue 4(4), and people with dementia at the end-of-life, issue 8(3). In addition, the Journal has advocated for moving 
beyond the person-centered paradigm of care to a relationship-based center of care (Adams \& Gardiner, 2005; Harris \& Keady, 2006; Nolan and Keady, 2007) and recognized the importance of having people with dementia and their families more involved in the co- construction of research (Keady, Williams, \& Hughes-Roberts, 2007; Mckillop \& Wilkinson, 2004), and programs and product development (Orpwood, Bjorneby, Hagen, Maki, Faulkner, \& Topo, 2004). And the Journal gave a forum to researchers and health care practitioners who questioned from epistemological, ethical and semantic perspectives the wisdom of clinically using the widely accepted term, mild cognitive impairment (Whitehouse \& Moody, 2006). Work undertaken by Jo Moriarty on the Innovative Practice section and Heather Wilkinson on the Book Reviews section (and prior to this Sue Hahn) have made significant contributions to the field and our thanks to them and all contributors over the years.

But where does the Journal go from here? Our role as social behavioral scientists is to continue asking critical questions that challenge strongly held assumptions and develop new conceptual models about how best to measure, treat, deliver service, and care for people with dementia and their families. The Journal needs to continue its role as being an open forum to discuss cutting edge ideas and an arena to present data that test and re-test accepted and proposed interventions that have the potential to improve the quality of life and quality of care for people with dementia and their families. For as one man with dementia once told one of the editors, "I'm dying with Alzheimer's disease. I know that...What you need to do -what they [researchers] need to do - is help me figure out how to live with it" (Harris, 2002, xiii).

\section{References}

Adams, T., \& Gardiner, P. (2005). Communications and interactions with dementia care triads. Dementia: The International Journal of Social Research and Practice, 4(2), 185-205.

Aubeeluck, A., \& Buchanan, H. (2006). Capturing the Huntington's disease spousal carer experience. Dementia: The International Journal of Social Research and Practice, 5(1), 95-116.

Cayton, H. (2004). Telling stories: choices and challenges on the journey of dementia. Dementia: The International Journal of Social Research and Practice, 3(1), 9-17.

Cloffi, J. M., Fleming, A., Wilkes, L., Sinfield, M., \& Le Mlere, J. (2007). The effects of environmental change on residents with dementia. Dementia: The International Journal of Social Research and Practice, 6(2), 215-231.

Davis, S., Byers, S., Nay, R., \& Koch, S. (2009). Guiding design of dementia friendly environments in residential care settings: Considering the living experience. Dementia: The International Journal of Social Research and Practice, 8(2), 185-203.

Fazio, S., \& Mitchell, D. (2009). Persistence of self in individuals with Alzheimer's disease: Evidence from language and visual recognition. Dementia: The International Journal of Social Research and Practice, 8(1), 39-39.

Harris, P. B. (2002). The Person with Alzheimer's disease: Pathways to Understanding the Experience. Baltimore, MD: The Johns Hopkins University Press.

Harris, P. B., \& Keady, J. (2006). Editorial. Dementia: The International Journal of Social Research and Practice, 5(1), 5-9.

Hicks-Moore, S. L., \& Robinson, B. A. (2008). Favorite music and hand message. Dementia: The International Journal of Social Research and Practice, 7(1), 95-108.

Iliffe, S., \& Manthorpe, J. (2007). Editorial: Following the trajectory of dementia: The NICE/SCIE guidelines. Dementia: The International Journal of Social Research and Practice, 6(1), 7-9. 
Keady, J., \& Harris, P. B. (2002). Editorial. Dementia: The International Journal of Social Research and Practice, 1(1), 5-6.

Keady, J., Williams, S., \& Hughes-Roberts, J. (2007). 'Making Mistakes': using Co-Constructed Inquiry to illuminate meaning and relationships in the early adjustment to Alzheimer's disease a single case study approach. Dementia: The International Journal of Social Research and Practice, 6(3), 343-364.

Knauss, J., \& Moyer, D. (2006). The role of advocacy in our adventure with Alzheimer's disease. Dementia: The International Journal of Social Research and Practice, 5(1), 67-72.

Malone, M. L., \& Camp, C. L. (2007). Montessori-based dementia programming: Providing tools for engagement. Dementia: The International Journal of Social Research and Practice, 6(1), 150-156.

McKillop, J., \& Wilkinson, H. (2004). Make it easy on yourself! Advice to researchers from someone with dementia on being interviewed. Dementia: The International Journal of Social Research and Practice, 3(2), 117-126.

Nolan, M., \& Keady, J. (2007). Editorial. Dementia: The International Journal of Social Research and Practice, 6(3), 323-326.

Orpwood, R., Bjorneby, S., Hagen, I., Maki, O., Faulkner, R., \& Topo, P. (2004). User involvement in dementia product development. Dementia: The International Journal of Social Research and Practice, 3(3), 263-279.

Parker, J., Young, A., \& Rogers, K. (2010). 'My Mum's Story': A Deaf daughter discusses her Deaf mother's experience of dementia. Dementia: The International Journal of Social Research and Practice, 9(1), 5-20.

Pearlin, L. I., Harrington, C., Lawton, M. P., Montgomery, R. J. V., \& Zarit, S. H. (2001). An overview of the social and behavioral consequences of Alzheimer's disease". Aging \& Mental Health, 5(Supplement 1), S3-6.

Sabat, S. (2001). The Experience of Alzheimer's disease: Life through a Tangled Veil. Oxford, UK: Blackwell.

Sterin, G. (2002). Essay on a word: A lived experience of Alzheimer's disease. Dementia: The International Journal of Social Research and Practice, 1(1), 7-10.

Tremont, G., Davis, J. D., Bishop, D. S., \& Fortinsky, R. H. (2008). Telephone-delivered psychosocial intervention reduces burden in dementia caregivers. Dementia: The International Journal of Social Research and Practice, 7(4), 503-520.

Van Hoof, J., \& Kort, H. S. M. (2009). Supportive living environments: A first concept of a dwelling designed for older adults with dementia. Dementia: The International Journal of Social Research and Practice, 8(2), 293-316.

Weyl, M. (2009). Love song at the end of the day: A wife's journey. Dementia: The International Journal of Social Research and Practice, 8(1), 9-15.

Wilkinson, H., \& Weaks, D. (2008). Editorial: Hearing the voices in the policy-practice-research nexus: the importance of the knowledge exchange process for people with dementia. Dementia: The International Journal of Social Research and Practice, 7(4), 427-233.

Whitehouse, P. J., \& Moody, H. R. (2006). Mild Cognitive Impairment: The hardening of the categories. Dementia: The International Journal of Social Research and Practice, 5(1), 11-25. 